\title{
Safety of Future NPPs Must Not Be in Conflict with Economics
}

\author{
Vladimir Petrochenko¹, Georgy Toshinsky ${ }^{1,2 *}$, Oleg Komlev ${ }^{1}$ \\ ${ }^{1}$ JSC “AKME-Engineering”, Moscow, Russia \\ ${ }^{2}$ JSC “SSC RF-IPPE”, Obninsk, Russia \\ Email: *toshinsky@ippe.ru
}

How to cite this paper: Petrochenko, V., Toshinsky, G. and Komlev, O. (2016) Safety of Future NPPs Must Not Be in Conflict with Economics. World Journal of $\mathrm{Nu}$ clear Science and Technology, 6, 284-300. http://dx.doi.org/10.4236/wjnst.2016.64026

Received: August 12, 2016

Accepted: October 21, 2016

Published: October 25, 2016

Copyright $\odot 2016$ by authors and Scientific Research Publishing Inc. This work is licensed under the Creative Commons Attribution International License (CC BY 4.0).

http://creativecommons.org/licenses/by/4.0/ (c) (i) Open Access

\begin{abstract}
The conflict between safety and economics requirements is peculiar to the present nuclear power (NP). The main point of the conflict is that for traditional type reactors the increase of requirements to safety of nuclear power plants (NPP) worsens their economical characteristics. This is caused by large potential energy accumulated in reactor coolant. In the presented paper the opportunity and expediency of changeover to reactors with heavy liquid-metal coolants (HLMC) in future NP is grounded. First of all, this refers to lead-bismuth coolant (LBC) mastered in the process of operating nuclear submarines (NS) reactors. The reactor facilities (RFs) of that type cannot cause destruction of defense barriers and make possible deterministic elimination of severe accidents with catastrophic radioactivity release. So it will make possible to eliminate the highlighted conflict and reasons for existence of population's radiophobia. Lead-bismuth fast reactor SVBR-100 with electric power of $100 \mathrm{MWe}$ is the reactor facility of that type. The effect of accumulated in coolant potential energy on safety and economics is considered. Main specific features of SVBR-100 technology providing a high level of inherent self-protection and passive safety are presented.
\end{abstract}

\section{Keywords}

SVBR-100, Reactor, Lead-Bismuth Coolant, Nuclear Power Plant, Inherent Self-Protection, Passive Safety

\section{Introduction}

The problem of NPP safety assurance that slightly quietened after happening of Chernobyl disaster has become more acute after the accident occurred at NPP Fukushima 1. In certain countries that problem was put at the political level. 
At the same time, further increase in safety requirements, which important quantity criterion is a value of probability of happening of the severe accident requiring population evacuation, can cause loss in competitiveness of NP based on use of traditional type reactors. Safety of such type reactors is mainly proved by probabilistic analysis methods (PSA).Just those reasons result in the necessity for future changeover to the reactors with a much higher level of inherent self-protection. In such reactors the severe accidents, which require population evacuation, will be deterministically eliminated.

First the necessity to develop those reactors was highlighted in 1985 in paper [1], in which such type reactors were named as inherently safe reactors. Detailed justification in the necessity to develop those reactors and general principles of their designing was summarized in 1990 in paper [2] (after happening of Chernobyl disaster). In that paper it was pointed out that for the population the opportunity of catastrophic consequences caused by the nuclear accident was much more important than extremely low possibility of accident occurrence. That is considered as a radiophobia effect. However, in accordance with the reliable statistical data [3], man-caused risks arisen due to operation of industrial enterprises and their fuel-energy infrastructure are by many orders higher than corresponding risks from the NP.

It can be presumed it is indeed the population radiophobia, which increased after the Fukushima-1 accidenthappened, was the reason of the fact that the NP was not mentioned as the carbon free option in the Global Agreement on Climate, which was signed by 196 parties on 12.12.2015 at UN Climate Change Conference held in Paris and purposed to replace the Kyoto Protocol. Nevertheless, in fact, taking into account inevitable future increases in electricity consumption due to population growth and scarcity of fresh water, there is no way to reduce significantly carbon emissions, but to develop the NP.

From the standpoint of nuclear community and educated people that sensing of NP is not rational. Nevertheless, radiophobia must be considered as an objective one and high safety of the NPP must be assured for the population, whose judgement is final, by "transparent" arguments and, if possible, without application of probabilistic analysis methods. It is much easier to convince the population in the NPP safety if it is provided by nature laws (e.g. lack of pressure in the reactor means that explosion cannot occur and so on), which people can understand on the basis of their own experience. It is more easily understood by the most of people than the results of probabilistic safety analyses.

Touching upon Russia reaction to the accident happened at NPP Fukushima 1, Director General of Rosatom State Atomic Energy Corporation Sergey Kirienko in the address to the Special Plenary Session of the International Congress on Advances in Power Plants, ICAPP-2011 (May 2-5, 2015, Nice, France) clearly argued for three stages of response actions [4].

The first near-future stage includes performance of stress-tests for all operating NPPs in Russia and their equipping with transportable sources of emergency electric and wa- 
ter supply, as well as proper training of the operating personnel. Now that task has been completed successfully.

The second medium-term stage consists in correction the NPP projects being under development and construction for the purpose of further enhancement of their safety level in conditions similar to those at NPP Fukushima 1.

The third long-term stage consists in changeover to construction of NPPs with natural safety reactors, in which severe accidents with catastrophic consequences have been deterministically eliminated by nature laws.

The term "natural safety" of the NPP that was offered in paper [5] with reference to lead cooled fast reactors (FR) is not quite appropriate as it dulls vigilance of both NPP developers and operating personnel. For developers and operating personnel the basic principle must be presumption of potential hazard in each nuclear reactor because of huge amount of radioactivity accumulated in the reactor.

The reactors, in which severe accidents requiring population evacuation have been deterministically eliminated, i.e. there are no reasons for their realization, should be rather named reactors with a high level of inherent self-protection. As it is shown below, the fast reactors with HLMC belong to such type reactors.

The technological basis for designing of those reactors is experience of development of two nuclear power technologies, namely: technology of fast reactors with sodium coolant (SFR) for civilian nuclear power, which could provide obtaining of a short doubling time of plutonium, and reactor technology developed in Russia for NS and based on application of HLMC-lead-bismuth eutectic alloy.

In the course of designing and operating the LBC cooled RFs at NSs a package of principal scientific and engineering problems on mastering of LBC technologies was solved [6], namely: assurance of corrosion resistance of structural materials; control of LBC quality and control of mass-transfer processes in the reactor circuit; assurance of personnel's radiation safety while carrying out works with the equipment contaminated with polonium-210 radionuclide; multiple LBC “freezing-unfreezing" in the RF.

These two already mastered technologies coupled in a single innovative technology could ensure elimination of the progressive conflict between safety requirements and economics requirements that is typical for NPPs with traditional type reactors.

The highlighted conflict is expressed in such a way that for enhancement of safety of such reactors it is required to increase a number of safety systems and defense-in-depth barriers that is conditioned by natural properties of used coolants. That results in decrease of investment attractiveness of NPP projects due to growth of the value of specific capital costs, and for their restraint it is required to increase the reactor unit capacity that is a cause of raise in the total costs of NPP construction and construction terms.

In the paper the following issues are considered: the opportunity and expedience of changeover in the future NP to technologies of FRs with HLMC, effect of potential energy accumulated in the RF coolant on NPP safety and economics and typical features of technology of modular Lead-Bismuth Fast Reactors (SVBR-100).The paper reveals due to what technical solutions realized in the SVBR-100 design the high level of 
inherent self-protection and passive safety is assured that makes possible elimination of the conflict between safety and economics requirements peculiar to traditional type RFs.

\section{The Opportunity and Expedience of Changeover to New Nuclear Technologies in the Future NP}

Use of HLMC in FRs provides the reactor with important properties of inherent selfprotection regarding to the certain severe accidents requiring the population evacuation. This is determined by those nature properties of HLMC as high boiling point and chemical inertness upon interaction with water and air, and thus being coupled with a proper design of the reactor, it makes possible deterministically eliminate such accidents.

At this point, the backgrounds for simplification of the reactor facility (RF) design arise due to elimination of the number of safety systems required in the RFs with other coolants. So it allows for NPPs realized on the basis of HLMC cooled FRs to be not only safer, but more economical as compared with NPPs based on traditional thermal reactors.

It is proved by the results of development of conceptual design of the large power NPP with SVBR-100 type reactors [7]. In Table 1 the technical and economical characteristics of different type electric power plants are compared [8].

Therefore, in conditions of existing low costs on natural uranium and services on its enrichment the new incentive for development of NPP $s$ with fast reactors can appear: instead of the "plutonium factory" building up plutonium at high paces, that is the construction of NPPs on the basis of LBC cooled FRs, which are self-protected against the severest accidents, with lower values of the specific capital costs and cost of produced electricity. It can be expected that at the first stage of implementation of FRs with LBC in the NP the opened nuclear fuel cycle (NFC) with postponed reprocessing of the spent nuclear fuel (SNF) will be economically expedient regardless of the significantly higher (approximately by a factor of 2.5) specific (per $1 \mathrm{~kW}-\mathrm{h}$ ) consumption of natural

Table 1. Comparative parameters of different power plants.

\begin{tabular}{|c|c|c|c|c|c|}
\hline Parameter name and measurement unit & $\begin{array}{l}\text { NPP based on } \\
\text { SVBR-75/100 }\end{array}$ & $\begin{array}{l}\text { NPP based on } \\
\text { VVER-1500 }\end{array}$ & $\begin{array}{l}\text { NPP based on } \\
\text { VVER-1000 }\end{array}$ & $\begin{array}{l}\text { NPP based } \\
\text { on BN-1800 }\end{array}$ & $\begin{array}{c}\text { FPP based } \\
\text { on PGU-325 }\end{array}$ \\
\hline 1. Installed power of the unit, MWe & 1625 & 1550 & 1068 & 1780 & 325 \\
\hline 2. Number of units at the plant & 2 & 2 & 2 & 2 & 10 \\
\hline 3. Share of electric power used to operate the plant, $\%$ & 4.5 & 5.7 & 6.43 & 4.6 & 4.5 \\
\hline 4. Net power plant unit efficiency, $\%$ & 34.6 & 34.4 & 33.3 & 43.6 & 44.4 \\
\hline 5. Specific capital cost, $\$ / \mathrm{kW}$ & $\begin{array}{c}\left.610^{\star}\right) \\
\left.550^{\star *}\right)\end{array}$ & 625 & 819.3 & 860 & 600 \\
\hline 6. Design-based cost of produced electricity, cent $/ \mathrm{kW} \cdot \mathrm{h}$ & 1.3 & 1.35 & 2.02 & 1.6 & 1.75 \\
\hline
\end{tabular}

*) The additional margin cost of $\sim 17 \%$ (over the normative one) has been introduced that is $60 \%$ of the cost of the RF equipment.

${ }^{* *}$ ) With due account of realizing the opportunities to changeover to the over-heated steam or to increase the temperature of the fuel elements claddings up to $650^{\circ} \mathrm{C}$. 
uranium. As an example, that opportunity is demonstrated by the results given in $\mathrm{Ta}$ ble 1. It could be expected that those reactors would be competitive with NPPs on the basis of thermal reactors and fossil power plants (FPP), because NP development in market conditions is not possible without successful competitiveness.

Of course, in the far future upon significant increase of the cost of natural uranium and costs of SNF storage, changeover to the closed NFC will become economically expedient. At this point, FRs with HLMC will operate in a mode of fuel self-providing with a core breeding ratio that slightly exceeds 1 . Only after experience of operation of those reactors at the demonstrational prototypes is gained, it would be possible to talk about their wide use in the NP. Using the expression of American Admiral Hyman G. Rickover known as the "Father of the Nuclear Navy", now these are "paper" reactors, though LBC was mastered in conditions of operating NS reactors.

The time for economically justified wide implementation of any type FRs and the structure of future NP i.e. proportion of thermal and fast reactors will be determined by economic indices of the latter (firstly by a value of specific capital costs).

Provided that FRs are cheaper in comparison with VVER (PWR) type reactors (most likely it is expected for FRs with HLMC), the NP structure will gradually become a single-component one that is with FRs only and their implementation will be determined by the level of technological readiness. If the breeding ratio of those FRs is of about 1 , then in case the own plutonium or plutonium from TR SNF (or warehouse reserves) is in deficiency, the required pace of NP development before changeover to the closed NFC must be provided by the starting loads of such FRs, which can be manufactured on the basis of enriched uranium.

In case FRs will be more expensive than VVER (PWR) type reactors with due account of the NFC cost, thus in conditions of deficiency of cheap natural uranium it will be expedient to have a two-component structure of the NP. Then to lessen the share of more expensive FRs a high value of breeding ratio is required (in other words, a minimal doubling time of plutonium that can be only provided by SFR type reactors).

The priority level of requirements of economic competitiveness for innovative nuclear energy systems (INES) is emphasized in the Report of Phase 1A of the International Project on Innovative Nuclear Reactors and Fuel Cycles (INPRO) [9]. In the proposed basic principles, it is highlighted that with account of all costs and credits, the cost of energy from innovative nuclear energy systems must be competitive with that from alternative energy sources, otherwise the alternative technologies will squeeze nuclear technologies out of the market. The comparative assessment of investment attractiveness of the innovative nuclear energy systems must take into account the total costs on the life-cycle including the costs on technology demonstration.

The higher NP competitiveness is the more opportunities for NP development will be both due to own resources (an opportunity to increase the investment share in the tariff) and borrowed financing resources (reduction of the capital repayment term).

From that point of view, the "early start" of FRs with a closed NFC under low costs of natural uranium can result in worsening of economic characteristics, reduction of NP 
investment opportunities and, as a consequence, decrease in paces of NP development. At the same time, for reasons of power safety the governments in certain countries can support development of the NP and FRs with a closed NFC in particular even with a high cost of electricity i.e. similar to development of renewable energy sources.

As safety characteristics and economic indices of the NPP strongly depend on potential energy accumulated in the reactor [10], it should consider that effect in details.

\section{Effect of Potential Energy Accumulated in Coolant on Safety and Economics}

Over the historically short time of NP development, operation of NPPs with different type reactors was followed by a number of low probability accidents of the various severity extent. These accidents caused strong radioactivity release into the environment and/or considerable economical losses. These were such accidents as Three Mile Island Unit 2 accident in 1979 (the USA) that occurred at the pressurized water reactor, Chernobyl disaster at Unit 4 that occurred on 26 April 1986 (the former USSR), fire that happened in 1995 at SFR "Monju" (Japan) as a result of non-radioactive sodium leak in the intermediate circuit pipeline, disaster that happened in 2011 at NPP Fukushima 1 (Japan) at the boiling water reactors.

The initial events for the listed accidents are very unlike. These are such as personnel's errors, technical failures, defects in the reactor design and extremal external impacts. However, there is a common cause of severe consequences of all mentioned accidents. They are the result of release of various types of potential energy accumulated in different materials, first of all, in the RF coolant [10]:

- compression energy of water coolant;

- chemical energy of interaction of water steam with zirconium;

- chemical energy of interaction of hydrogen produced by steam-zirconium reaction with air oxygen;

- energy of chemical interaction of sodium with air oxygen.

Due to those accidents, in many countries the population trust in the NP safety was lost. In order to return the population confidence to the NP, the necessity to make corrections in the strategy of NP development, bearing in mind demands for large-scale NP development in the future.

In the system approach, safety and hazard are considered as interconnected concepts. Therefore, in order to understand better how to achieve a high safety level for the RF, the nature of hazard peculiar to nuclear reactors should be analyzed.

The hazard from the RF is determined by three factors:

1) radiation potential accumulated, i.e., total radioactivity (more exactly, radiotoxicity) contained in the RF;

2) residual heat release of fission products radioactive decay;

3) amount of radiotoxic products released into the environment upon different initial events.

The first and second hazard factors do not depend strongly on the RF type, because 
total radioactivity contained in the RF and determined mainly by the amount of fission products is associated primarily with thermal power of the reactor and fuel lifetime, i.e. with energy production. These factors are "inherently peculiar" to each RF and cannot be reduced.

The third factor depends strongly on the RF type and is determined by reactivity margin, reactivity feedbacks, design features, and potential energy accumulated in the RF materials (nuclear energy, internal thermal energy, coolant compression energy, chemical energy), which in an event of damage of defense barriers can cause huge exhaust of radiotoxicity into the environment. Therefore, the hazard associated with the $\mathrm{RF}$ (for the identical power levels and fuel lifetime) will be determined by the third factor that can be reduced at the stage of project designing.

That factor requires detailed consideration. The nuclear fission energy, which can be released under conditions of reactivity accidents (such as unauthorized insertion of positive reactivity higher than effective fraction of delayed neutrons, $\beta_{\text {eff }}$ ), can and must be minimized as early as at the stage of reactor designing by limitation of the reactivity margin, use of negative reactivity feedbacks, and various engineering solutions in the control and protection system (CPS), which should exclude an opportunity of prompt neutrons runaway in the reactor.

At the same time the potential (non-nuclear) energy accumulated in coolant used in the RF primary circuit is an inherent property of the coolant material and cannot be changed by engineering solutions.

Therefore, upgrade of safety of NPPs based on RFs with high amount of potential energy accumulated in coolant requires increase of the number of safety systems and defense-in-depth barriers, which decrease the probability of severe accidents (but do not eliminate deterministically the reasons for their occurrence) and weight of their consequences. Upon assessment of that probability, failures in the basic equipment, safety systems, defense barriers, and personnel's errors are considered as random events.

However, the results of safety substantiation by methods of PSA legalized in regulation documents as applicable to severe accidents, their probability being very low ( $10^{-6}$ per reactor-year and less) do not possess the credibility value as necessary. This is conditioned by high diversity and complication of the processes developing in conditions of the severe accident, lack of the certain initial data required for calculation, and many uncertainties in the available data.

Moreover, use of probabilistic analysis methods makes no sense upon consideration of such initial events, in which all active safety systems (or passive ones, which have been initiated by actuation of some mechanic devices), which are in a standby mode, and defense barriers can be disabled. For example, the over-normal external environmental effects or man-caused impacts, ill-intended people's actions can result in disastrous radioactivity release. A well-known fact is the explosions performed by terrorists at NPP "Lemoniz" (Spain) in 1978 and 1979 [11]. The importance to consider such scenarios is verified by the fact that they have also been addressed by the IAEA [12] be- 
cause the NPP with potential energy accumulated in the RF coolant in great amounts could be used by terrorists as an instrument of political blackmail.

After the accident happened at NPP Fukushima 1, several European countries put forward the following approach to safety requirements to IV Generation reactors: "Never More" i.e. a conception of near-zero radiologic risk for the population at any external initiating events [13]. However, in case of realization in practice, that approach, which eliminates the necessity to take protection measures and evacuate the population beyond the NPP site even in events of hypothetical ultimate accidents with total NPP damage and further total radioactivity release into the environment (the worst), will mean the NP end. Being unrealizable for reactors of all types, that requirement must not be accepted by countries and organizations responsible for NP development including the IAEA. This is confirmed by the fact that in the last version of IAEA safety requirements issued in 2012 after the Fukushima accident happened, in the list of external initiating events such requirement is absent [14]. Moreover, the approach to the risk of radiation influence on the population known as ALARA (as low as reasonable achievable) was replaced by principle ALARP (as low as reasonable practicable), which is reflecting more accurately the real abilities.

For that reason, for the future NP many countries began to consider the following approach to substantiation of NPP safety as the most expedient one. That is deterministic elimination of the necessity for population evacuation in events of any technically possible severe accidents in combination with a probabilistic approach for assessment of the frequency of accident occurrence including such severe accidents as core damage unless it is accompanied by release of potential energy that can cause destruction of protective barriers and subsequent release of radioactivity.

If we accept the same values for the risk of radioactivity release from different type RFs to be at a socially acceptable level, the number of safety systems and defense-indepth barriers, which strongly determine the NPP technical and economical characteristics, can be reduced provided of lower accumulation of potential (non-nuclear) energy stored in the RF, mainly in coolant. At this point, it is important that the high safety level at low value of potential energy stored in coolant can be achieved with absence of corresponding safety systems (and improvement of technical and economical parameters of the NPP) due to elimination of the causes for those severe accidents, i.e., deterministically.

The values of potential energy stored in different coolants, which were calculated using the reference data, are summarized in Table 2 [10].

When computing assessments were performed, the following components of potential energy were taken into account:

1) for water coolant some amount of stored thermal energy is converted into kinetic energy of steam expansion (assessment in Table 2 is performed for the adiabatic process) and a certain part is used for water evaporation that can cause loss of core cooling. Moreover, in an event of the severe accident while steam is chemically interacting with zirconium, thermal energy and hydrogen are released in large quanti- 
Table 2. The values of specific (per a volume unit) stored potential energy for different coolants.

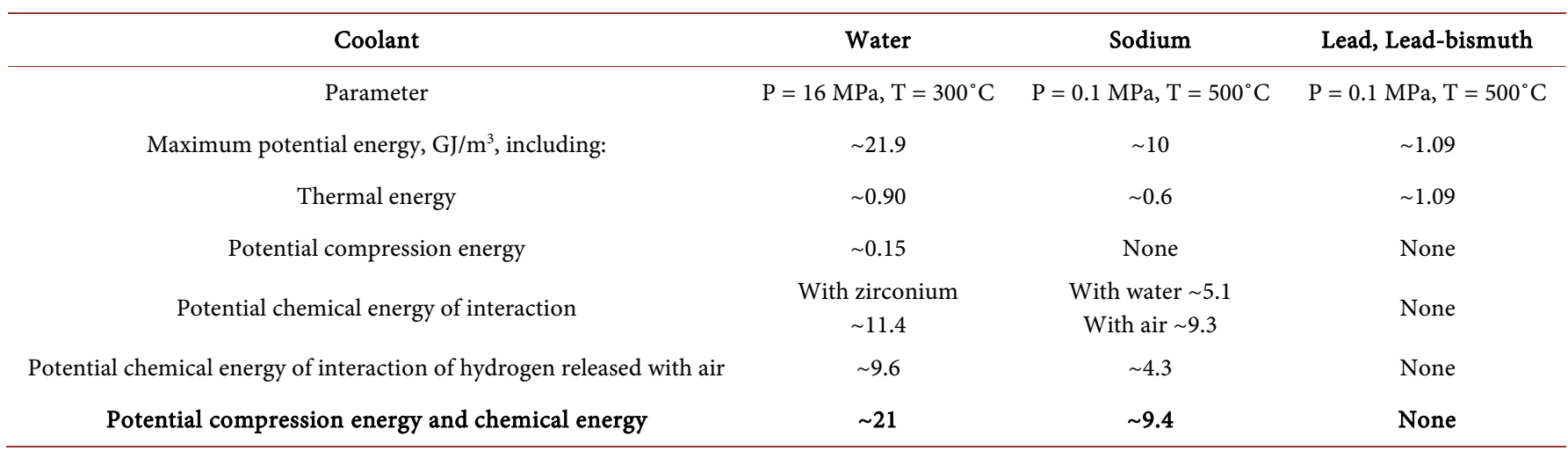

ties. hydrogen, in its turn, is a high-rating source of hazard;

2) for sodium coolant the release of stored chemical potential energy can be realized both while contacting with air, and while contacting with water (in that case the thermal energy and hydrogen are released);

3) for heavy liquid-metal coolants (lead-bismuth alloy, lead) and molten salts the stored thermal potential energy cannot be converted into kinetic energy, there is no significant release of energy in an event of coolant's chemical interaction with air, water or structural materials, there is no loss of core cooling in an event of tightness failure in the gas system.

Nevertheless, taking into account the material presented above, we cannot approve a priori that the RFs with coolants with large amount of stored potential energy are less safe than RFs with HLMC. The required level of safety is also achieved due to the NPP equipped with a necessary number and efficiency of defense-in-depth barriers and safety systems. However, these differently affect the NPP technical and economical parameters.

As a competitive price of electricity is an only criterion for access to the electricity market, because its quality is always standard and does not depend on the NPP safety level, obtaining of the highest (therefore, more competitive) economical characteristics must be the principal task of the NPP design. And safety must be at a socially acceptable level that is specified by regulation documents and is the same for all NPP types. Increase of safety characteristics over that level is justified if it is only obtained due to inherent self-protection properties without detriment to economic characteristics.

Along with that, proofs of safety for RFs with low value of potential energy stored in coolant will be much more accessible for population understanding than for RFs, which high safety level is justified by PSA methods. That will result in a higher level of social acceptability of NPPs with such RFs. For that reason, NPP projects with a higher (and more "transparent") level of inherent self-protection will have a better chance to win the tender.

Therefore, the NPPs based on RFs with HLMC possess prerequisites for finding the solution to the basic problems of NP, such as safety and economics. The other problems, namely: efficient use of power potential of natural uranium upon operating in the 
closed NFC, reduction of the risk of unauthorized proliferation of nuclear fissile materials (NFM), management of long-lived radioactive waste can be solved not only upon use of RFs with HLMC, but upon use of industrially mastered SFRs, which are technologically ready for wide implementation.

\section{Brief Description of the RF SVBR-100 Design [15]}

The flow diagram of RF SVBR-100 is shown in Figure 1. Hydraulic links over the LBC path are formed in the RMB without pipelines and valves (weak places). Four loops of the second circuit with vertical separators and multiple force circulation (MFC) pumps are shown. In the RMB the primary circuit gas system is designed to maintain the inert atmosphere (argon) above LBC free levels in the primary circuit. There is a passive heat removal system (PHRS).In an event of steam generator (SG) tube rupture the gas system condenser will be a steam condensate, and two bubblers are provided to receive a steam-gas mixture from the RMB gas volume over LBC level for protection of RMB vessel from steam pressure increase above the permissible limit.

The basic components of RF SVBR-100 are as follows: the RMB with a removable shielding plug and core; a set of control and protective system (CPS) drives; 2 main circulation pumps (MCP) of the primary circuit with gas-tight electric motors; 12 SG modules generating dry saturated steam; LBC technology equipment; internal equipment; four-loop circuit with MFC of the secondary circuit working medium; four-loop system of the PHRS; primary circuit gas system; steam-gas mixture receiving system. General layout of the RMB of SVBR-100 is shown in Figure 2. General layout of the RF is shown in Figure 3.

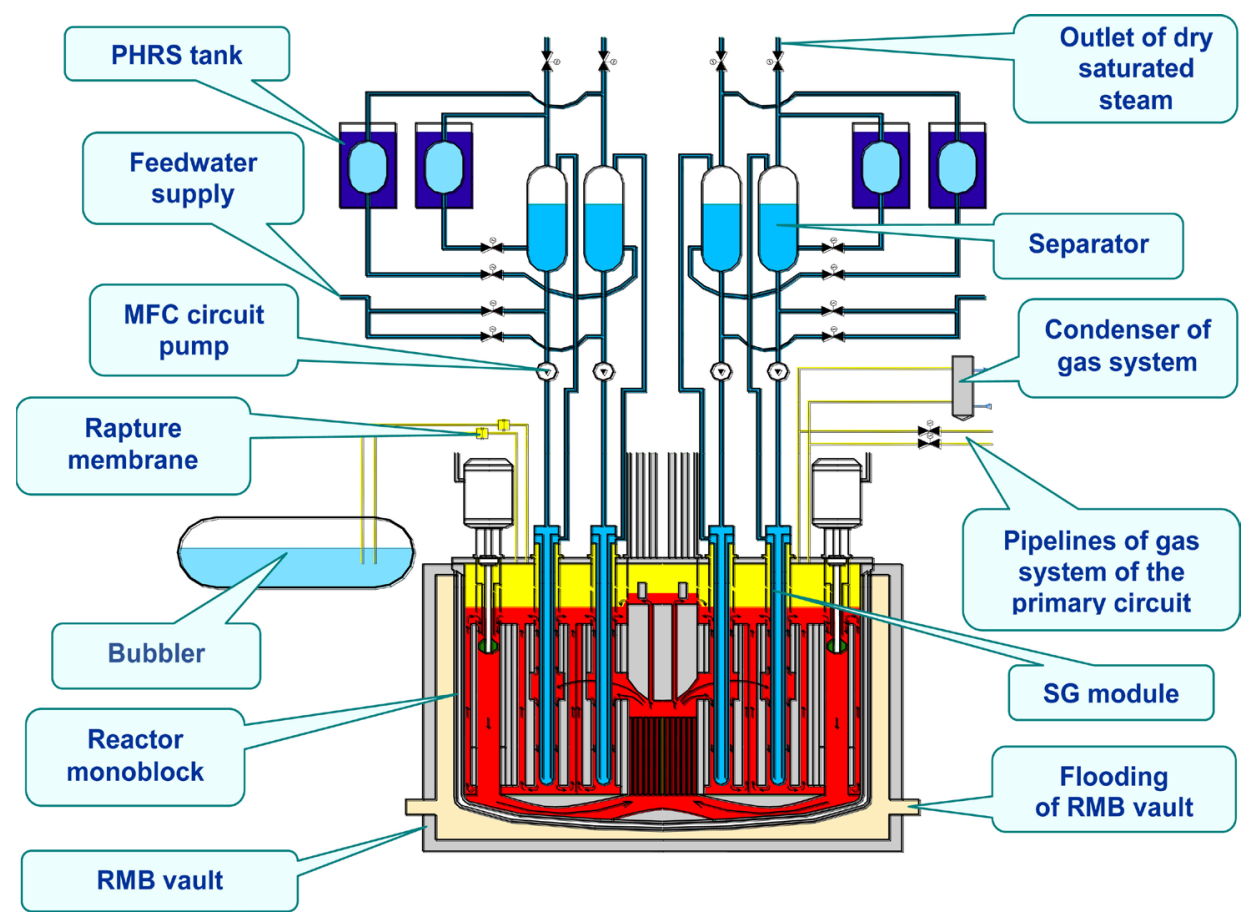

Figure 1. The flow diagram of RF SVBR-100. 


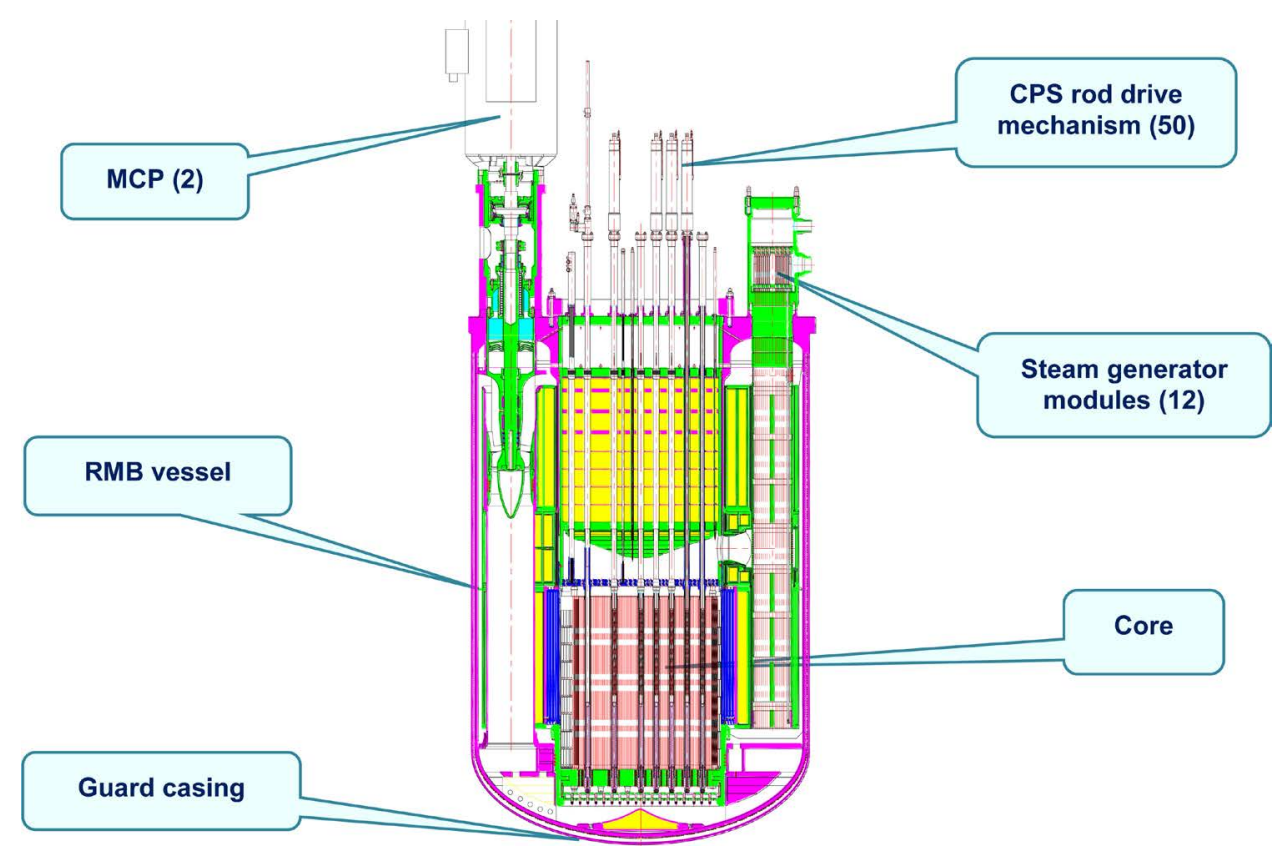

Figure 2. Layout of the SVBR-100 RMB.

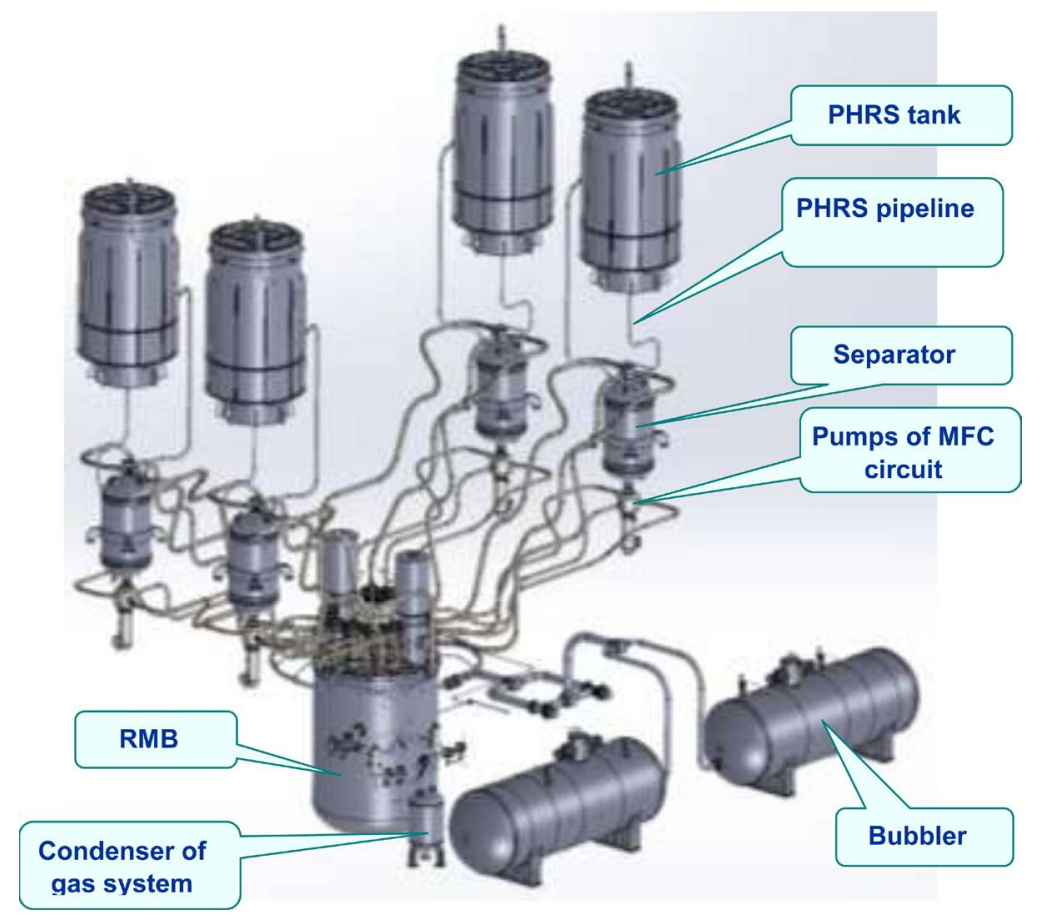

Figure 3. General layout of RF SVBR-100.

\section{Main Specific Features of the SVBR-100 Technology Providing a High Level of Inherent Self-Protection and Passive Safety}

- The high safety level resulting from natural properties of LBC (lack of excessive pressure and chemical inertness in events of contacting with water and air that is possible in accidental conditions). Upon monoblock design of the RF with the RMB 
having a protective casing, this eliminates an opportunity of LBC loss (loss of coolant accident) with core melting, reactor explosions and fires (lack of hydrogen release), which can be caused by internal reasons.

- Chemical compatibility of fuel $\left(\mathrm{UO}_{2}\right)$ with $\mathrm{LBC}$ eliminates the accidental situation with damage of fuel element cladding that can be developed in an event of large radioactivity release into coolant.

- Fuel pellets retain the main part of accumulated fission products. Fuel density approximately equals to coolant density (in case of melt, fuel does not sink). Therefore, there is no need in a core catcher.

- LBC retaining iodine, cesium and other fission products (with an exception of gaseous ones), which can ingress in it in an event of tightness failure in the fuel element cladding.

- Polonium is defining the radiation situation in an event of tightness failure in the RF gas system and requires providing of corresponding radiation safety measures. The concentration of polonium-210 formed in LBC under irradiation by bismuth neutrons is very low $\left(10^{-6} \%\right)$ and it forms thermodynamically resistant intermetallic compound with lead. Those factors reduce evaporation of polonium from LBC by a factor of $10^{9}$ and that provides a comparatively favorable radiation situation in an event of postulated tightness failure in the primary circuit or gas system pipelines operating without excess pressure. In the postulated events of LBC leakage radioactivity release significant decrease of due to "freezing" of coolant.Those measures were developed and realized while operating of LBC cooled RFs at the NSs. Developed radiation safety measures were very effective as nobody of the personnel (both military and civilian ones), who took part in the elimination of accidents consequences (about $20 \mathrm{t}$ of radioactive LBC leaked in the reactor compartment of facility $27 / \mathrm{VT}$ that was the first in the world LBC based reactor), got the polonium in-take dose that exceeded the permitted one [16].

- In all heat-removal circuits the level of coolant natural circulation sufficient enough for removal of residual heat release is provided. Heat removal via the SG is provided by four independent channels of the PHRS due to evaporation of water in the PHRS tanks with steam discharge into the atmosphere, grace period is 72 hours. In an event of postulated failure of four channels, it is provided that the reactor monoblock vault is flooded by water. Management of that accident that is considered as the accident being beyond the design basis is provided by feed of PHRS tanks or RMB vault from emergency sources of water $\left(\sim 2.5 \mathrm{~m}^{3} /\right.$ hour)and electricity supply (for example, fire engines and so on).

- The reactor possesses a negative void reactivity effect and negative temperature reactivity coefficient. In addition to emergency protection (EP) rods actuating by electric signals, the reactor is equipped with directly acting additional emergency protection (AEP) rods, which actuate according to increase in LBC temperature (fusible locks).The temperature margin of SVBR-100 is over 50 percent in power for the limiting core parameters. In the accidental conditions (reactor loop test) the fuel 
element with cladding made of ferrite-martensitic type steel that is corrosion-resistant in LBC can withstand emergency overheating up to $900^{\circ} \mathrm{C}$ without damage during 5 minutes. These all eliminate the unprotected transient overpower type accidents.

- In an event of simultaneous shutdown of both MCP of the and failure of the main EP system, self-protection of the RF is provided passively due to actuation of the AEP rods, inertial rundown of the MCP and natural circulation of coolants in heat-removal circuits. That excludes the unprotected loss of flow accidents.

- To localize the accident with leak in SG tubes, the steam condensers are provided in the primary circuit gas system. In an event of their failure it is provided that steam-gas mixture is passively discharged to the bubbler via rupture membranes. The scheme of LBC circulation in the RMB provides effective gravitational separation of steam bubbles on the LBC free level under the RMB lid.

- At the stage of storage of SNF elimination of radioactivity release is provided as follows: after removal from the reactor the fuel sub-assembly (FSA) is imbedded in a steel case filled with liquid lead, which then is put into the storage cell where removal of residual energy-release is realized passively due to natural circulation of atmospheric air. At this point, there are four safety barriers on the path of radioactivity release into the environment, namely: fuel pellet, fuel element cladding, hardened lead and leakproof case.

- Actually, in the process of operation no liquid radioactive wastes (LRW) are produced as refueling is performed without removal of coolant from the primary circuit and its further decontamination, which is a cause of formation of LWR in large quantities.

- In an event of the shutdown reactor and low level of residual energy-release, self-protection against unauthorized LBC "freezing" in the RF is provided by zero change of the LBC volume upon transition from a liquid state into solid one. Upon "freezing-unfreezing" of LBC, maintaining of the equipment operability is verified not only experimentally at large-scale prototypes but in conditions of operating of the NS RFs.

- To assess the safety potential of reactor SVBR-100, the preliminary calculation analysis of the consequences caused by a postulated severe accident was performed [17] under combination of such events as:

1) destruction of the protective shell of the reactor building,

2) damage of the reinforced concrete overlapping of the reactor box,

3) rupture of gas system pipelines in the reactor monoblock installed in the concrete vault below the ground level with direct contact of the free surface of lead-bismuth coolant under the monoblock lid and atmospheric air,

4) total blackout of the NPP.

That combination of initial factors is only possible in extreme events, such as military actions, terror attacks, nature disasters, which occur very rarely, and so on. The results of the performed calculation analysis have revealed that even in an event of extremely 
unfavorable atmospheric conditions, no population evacuation beyond a three-kilometer zone is required. For reactors with water or sodium coolants such combination of initial events can result in catastrophic consequences.

The performed analysis has revealed that RF SVBR-100 is not an amplifier of external impacts and, therefore, the scale of damages will be only determined by the energy of external impacts. Those type RFs assure their high resistance not only in events of single failures of the equipment and personnel errors but in events of premeditated ill-intentioned actions when all special safety systems operating in a standby mode can be intentionally disabled. At those reactors such catastrophic accidents as Chernobyl or Fukushima disasters as well as fires similar to that occurred at reactor "Monju" are impossible in principle or can be easily localized with a purpose to prevent population's exposure to irradiation beyond the NPP site (loss of heat sink type accidents). This is extremely viable for realization of NPP construction in developing countries where the level of terroristic threat is high.

\section{Conclusions}

The following conclusions can be made on the basis of the material presented above:

- Fast reactors with HLMC, in which there is no potential energy stored in the RF coolant that under the certain initial events can cause destruction of defense barriers makes possible deterministic elimination of severe accidents with catastrophic radioactivity release (that is caused by release of coolant potential energy) requiring population evacuation. That assures the higher level of social acceptability of the NP and gives additional competitive advantages.

- Construction of FRs as well as NP development on the whole can be only justified provided they produce electricity that is cheaper than electricity produced by the alternative power sources. With due account of larger duration of mastering and launching of new nuclear technologies, it can be expected that till the end of the century the VVER (PWR) type reactors operating in an open NFC with postponed reprocessing of the SNF will play the key role in the NP structure.

- First of all, large-scale development of NP is impeded by the population radiophobia and low level of competitiveness. These problems can be solved by use of FRs with HLMC that are the point of the present paper. The other impeding problems are as follows: very low efficiency of use of natural uranium energy potential in thermal reactors, postponed problem of handling the increasing amount of SNF, assurance of the NFM nonprolife ration mode. These problems can be solved not only FRs with HLMCs but also with mastered sodium FRs, which operate in the closed NFC.

- Use of HLMC cooled FRs in the NP can ensure elimination of the progressive conflict between safety requirements and economics requirements that is typical for traditional type reactors as improvement of safety is not required increasing of the number of safety systems and defense-in-depth barriers, but it is achieved due to the higher level of inherent self-protection, i.e. without detriment to economic characteristics.SVBR-100 using LBC mastered in conditions of operating NSs is the fast 
reactor of that type.

- It is planned that the technology of SVBR type reactors will be realized in construction of a first-of-a-kind experimental-industrial power-unit (EIPU). The Project is being realized within the framework of state-private partnership with joint venture JSC "AKME-engineering" established on a parity basis by the State Atomic Energy Corporation "Rosatom" and Limited Liability Company "Irkutskenergo". At present JSC "AKME-engineering" has received a "Rostechnadzor" license for placing of the EIPU in Dimitrovgrad (Ulyanovsk region).

- In the nearest future the tasks are as follows: development of the EIPUSVBR-100 design to the stage of receiving of Construction License; development of proposals for serial production of the NPP, in which the opportunities for improvement of technical and economical characteristics providing competitiveness of small and medium power plants with alternative power sources must be realized to the full extent. That can be achieved due to elimination of excessive conservatism of technical solutions adopted in the EIPU design and use of progressive technical solutions (namely: changeover to once-through SGs generating overheated steam and so on), which require development of additional R\&D.

\section{Acknowledgements}

The authors would like to thank SSC RF-IPPE employees S.V. Budarina, K.G. Melnikov, I.V. Tormyshev for the assistance in preparation of the present paper.

\section{References}

[1] Spievak, I. and Weinberg, A.M. (1985) Inherently Safe Reactors. Annual Review of Energy, 10, 431-462. http://dx.doi.org/10.1146/annurev.eg.10.110185.002243

[2] Forsberg, C.W. and Weinberg, A.M. (1990) Advanced Reactors, Passive Safety, and Acceptance of Nuclear Energy. Annual Review of Energy, 15, 133-152. http://dx.doi.org/10.1146/annurev.eg.15.110190.001025

[3] Arutyunyan, R.V. (2013) Have We Got Safety Culture? Atomnaya Strategiya XXI, 83, 9-11 (in Russian) http://www.proatom.ru/

[4] (2011) Nucleonics Week, Vol. 52, No. 19, 12 May 2011, 6-7.

[5] Orlov, V.V., Avrorin, E.N., Adamov, E.O., et al. (1992) Nontraditional Concepts of NPPs with Natural Safety. Atomnaya Energiya, 72, 317-328 (in Russian).

[6] Toshinsky, G.I., Komlev, O.G., Stepanov, V.S., et al. (2008) Innovative Nuclear Technology Based on Modular Multi-purposed Lead-Bismuth Cooled Fast Reactors. Progress in Nuclear Energy, 50, 170-178. http://dx.doi.org/10.1016/j.pnucene.2007.10.025

[7] Toshinsky, G.I., Komlev, O.G., Stepanov, V.S., et al. (2006) Nuclear Power Development in Market Conditions with Use of Multi-Purpose Modular Fast Reactors SVBR-75/100. Nuclear Engineering and Design, 236, 1490-1502.

[8] Zrodnikov, A.V., Chitaykin, V.I., Toshinsky, G.I., et al. (2001) NPP Based on Reactor Modules SVBR-75/100. Atomnaya Energiya, 91, 415-425 (in Russian).

[9] Report on Phase 1A of the International Project on Innovative Nuclear Reactors and Fuel Cycles (INPRO). IAEA-TECDOC-1362, 2004.

[10] Toshinsky, G.I., Komlev, O.G., Tormyshev, I.V. and Petrochenko, V.V. (2013) Effect of Po- 
tential Energy Stored in Reactor Facility Coolant on NPP Safety and Economic Parameters. World Journal of Nuclear Science and Technology, 3, 59-64.

http://www.scirp.org/journal/wjnst

http://dx.doi.org/10.4236/wjnst.2013.32010

[11] Nuclear Terrorism. http://www.gochs.info/p669.htm

[12] IAEA (February 2006) Advanced Nuclear Plant Design Options to Cope with External Events. IAEA-TECDOC-1487.

http://www-pub.iaea.org/MTCD/publications/PDF/te_1487_web.pdf

[13] Ammirabile, L. European Project SARGEN_IV: Safety Approach and Assessment of GEN IV Reactors.

http://www.iaea.org/NuclearPower/Downloadable/Meetings/2013/2013-02-26-02-27-TM-S FR/day-1/4-L.Ammirabile-EC.pdf

[14] IAEA, Vienna (2012) SAFETY OF NUCLAR POWER PLANTS: DESIGN, Specific Safety Requirements. IAEA Safety Standards Series No. SSR-2/1.

[15] Dzangobegov, V.V., Stepanov, V.S., Dedul, A.V., et al. (2014) Reactor Plant SVBR-100 for Modular-Type Small-and-Medium Power Nuclear Power Plants. Proceeding of 4 th Conference “Heavy Liquid-Metal Coolants in Nuclear Technologies (HLMC-2013)", Paper № 10, Vol. 1, 23-26 September 2014, Obninsk, 77-86 (in Russian).

[16] Pankratov, D.V., Yefimov, Ye.I., Toshinskyand, G.I. and Ryabaya, L.D. (2005) Analysis of Polonium Hazard in Nuclear Power Installations with Lead-Bismuth Coolant. Proc. of International Congress on Advances in Nuclear Power Plants, CD-ROM, Paper No. 5497, Seoul, Korea.

[17] Bolhovitinov, V.N., Pankratov, D.V., Toshinsky, G.I., et al. (2003) Assessment of Radiation Consequences Caused by Large Tightness Failure in the Primary Circuit Gas System of RF SVBR-75/100 with Simultaneous Coolant Heating up to $600{ }^{\circ} \mathrm{C}$. Paper No. 2203 (CDROM), 2 nd Conference "Heavy Liquid-Metal Coolants in Nuclear Technologies (HLMC2003)" Held within the Frameworks of Russian Scientific \& Technical Forum "Fast Neutron Nuclear Reactors" Devoted to the 100 th Anniversary of A.I. Leypunsky, Obninsk, Russia (in Russian). 


\section{Abbreviations}

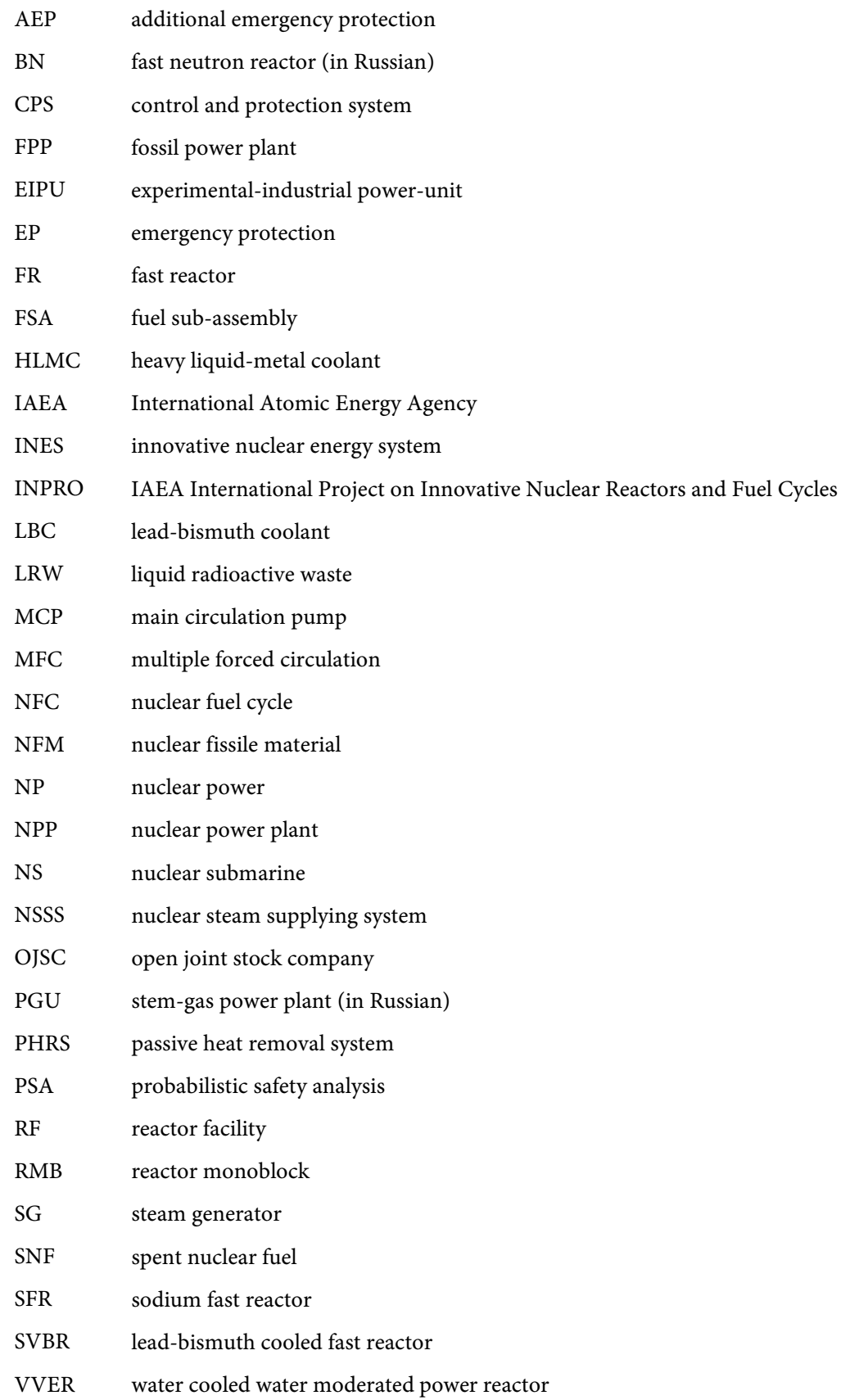


Submit or recommend next manuscript to SCIRP and we will provide best service for you:

Accepting pre-submission inquiries through Email, Facebook, LinkedIn, Twitter, etc. A wide selection of journals (inclusive of 9 subjects, more than 200 journals)

Providing 24-hour high-quality service

User-friendly online submission system

Fair and swift peer-review system

Efficient typesetting and proofreading procedure

Display of the result of downloads and visits, as well as the number of cited articles

Maximum dissemination of your research work

Submit your manuscript at: http://papersubmission.scirp.org/

Or contactwjnst@scirp.org 